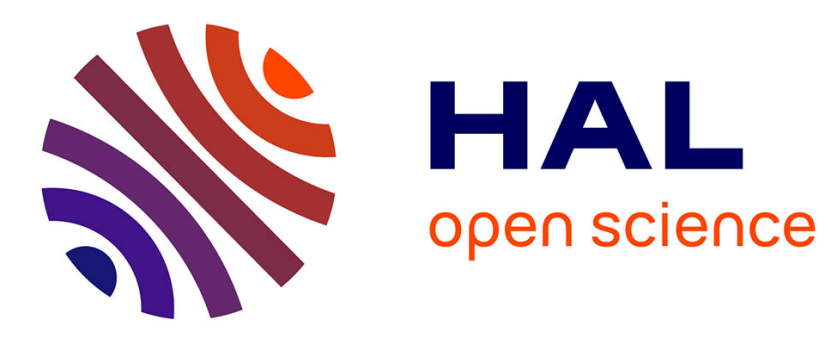

\title{
Spacecraft worst-case surface charging: On the importance of measuring the electron emission yield under representative environmental conditions
}

Jean-Charles Matéo-Vélez, Mohamed Belhaj, Sarah Dadouch, Pierre Sarrailh, Sébastien Hess, Denis Payan

\section{To cite this version:}

Jean-Charles Matéo-Vélez, Mohamed Belhaj, Sarah Dadouch, Pierre Sarrailh, Sébastien Hess, et al.. Spacecraft worst-case surface charging: On the importance of measuring the electron emission yield under representative environmental conditions. IEEE Transactions on Plasma Science, 2019, 47 (8), pp.3790-3795. 10.1109/TPS.2019.2925435 . hal-02301118

\section{HAL Id: hal-02301118 \\ https://hal.science/hal-02301118}

Submitted on 30 Sep 2019

HAL is a multi-disciplinary open access archive for the deposit and dissemination of scientific research documents, whether they are published or not. The documents may come from teaching and research institutions in France or abroad, or from public or private research centers.
L'archive ouverte pluridisciplinaire HAL, est destinée au dépôt et à la diffusion de documents scientifiques de niveau recherche, publiés ou non, émanant des établissements d'enseignement et de recherche français ou étrangers, des laboratoires publics ou privés. 


\title{
Spacecraft worst-case surface charging: On the importance of measuring the electron emission yield under representative environmental conditions
}

\author{
J.-C. Mateo-Velez, M. Belhaj, S. Dadouch, P. Sarrailh, S. L. G. Hess, D. Payan
}

\begin{abstract}
To represent the time spent by space materials on ground before launch, the measurement of secondary electron emission properties is performed after long duration exposure to ambient atmosphere and humidity. The observed change with respect to pristine samples have an impact on the estimation of worst-case surface charging levels in geostationary orbit, especially for a spacecraft in eclipse. It is therefore recommended to adequately outgas the samples with respect to the expected flight conditions and ageing effects.
\end{abstract}

Index Terms-spacecraft charging, electron emission, electrostatic discharges, testing, simulation

\section{INTRODUCTION}

$\mathrm{E}$ stimating worst-case surface charging remains a challenge because it depends on the complex interaction between the spacecraft and its environment. One of the key physical processes at play is the electron emission of surface materials exposed to ambient electron irradiation. Flight data have shown that hundreds to thousands of volts of negative potentials are observed on spacecraft at geosynchronous orbit (GEO) when the spacecraft is in the midnight sector, especially when it is in Earth eclipse [1]-[2]-[3]. High differential voltages of surface dielectrics with respect to the structure have also been measured in the past [4] but too few spacecraft are equipped with dedicated instrumentation to allow extrapolating to other situations. Ground experiments are performed by the space industry on small sized coupons to test the response of materials sensitive to charging hazards under flight representative conditions. These data can be used as is and/or serve as inputs of larger scale simulations using numerical tools [5]-[6]-[7]-[8] that combine the three-dimensional geometrical description of a given spacecraft, the physical mechanisms ruling the behavior of its surface materials and, finally, the energy distribution of worst-case environments [9]-[10].

This paper shows how the ground experimental conditions used to measure the electron emission yield (EEY) under

This work was supported by CNES R\&D program 2017.

J.-C. Matéo-Vélez, M. Belhaj S. Dadouch, P. Sarrailh, S. L. G. Hess are with ONERA / DPHY, Université de Toulouse, F-31055 Toulouse - France (e-mail: mateo@onera.fr).

Denis Payan is with CNES, FR-31401, Toulouse (e-mail: denis.payan@onera.fr) electron irradiation have an impact on the resulting data and subsequently on the extrapolation to space conditions. Due to the very low escape depth of secondary electrons (a few nanometers), EEY is highly sensitive to first mono-layers. Studies of the electron emission behavior of pi-bonded organic structures as well as bare metals show that the probability of electron emission can change dramatically at sub-monolayer levels and that the change tends to flatten out at a few monolayers ([11]-[15]).

We first present the effect of material surface state sensitivity on EEY. In particular, we show the impact of the contamination and/or oxidation layers that form at the surface of technical materials, i.e. the materials used in spacecraft technologies, because of their inevitable exposure to the atmosphere. Finally, we show how these changes result in different results from a worst case surface charging analysis.

Section II presents the experimental apparatus used to measure the EEY in various conditions aiming at representing the main steps from manufacturing to launch to space environment. Section III presents and analyzes the results of the experimental campaign as for the effect of the evolution of the surface composition. Section IV describes the numerical simulation study performed to identify the effect of EEY measurements on the estimation of worst-case surface charging under GEO environments. The numerical results are presented in Section V and discussed in Section VI.

\section{EXPERIMENTAL APPARATUS}

\section{A. Facility}

The surface analysis by means of X-ray Photoelectron Spectroscopy (XPS) as well as EEY measurements were performed in DEESSE facility located at ONERA Toulouse Center. DEESSE, represented in Fig.1, is entirely dedicated and designed to the study of electron emission and to surface analysis. A dry turbo-molecular pump associated with an oil-free primary pump allows the system being maintained at an Ultra-High-Vacuum (UHV) level. The sample holder allows the variation of the electron incidence angle from $0^{\circ}$ (normal incidence angle) to $80^{\circ}$. An ELG electron gun from Kimball Physics Instrument was used. The electron beam was pulsed during EEY measurements to limit the surface conditioning 
effect (electron beam induced surface modification). A Tectra ion gun used for surface sputtering has an energy range from $50 \mathrm{eV}$ to $5000 \mathrm{eV}$. Argon gas is injected through a micro leakage valve and atoms are excited by microwaves generated by a microwave magnetron with a $2.45 \mathrm{GHz}$ frequency. The Omicron hemispherical electron analyzer is used. It can record spectra from 2 to $2000 \mathrm{eV}$. Prior to measurements, the tank was baked to $180^{\circ} \mathrm{C}$ for 48 hours.

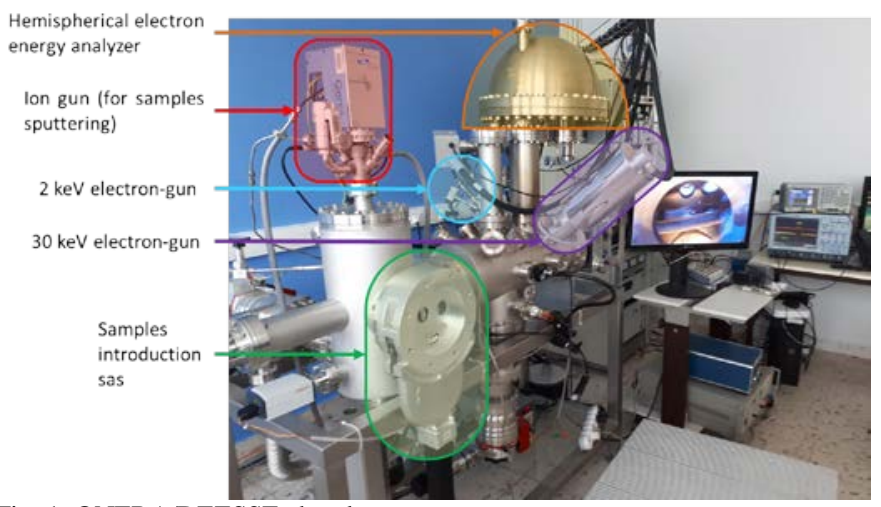

Fig. 1. ONERA/DEESSE chamber apparatus

\section{B. EEY measurement techniques}

To measure the EEY parameters, the incident electron current $I_{f}$ and the sample current $I_{S}$ were monitored. $I_{f}$ was measured using a faraday cup. The sample was negatively biased with respect to the grounded vacuum tank during Is measurement in order to avoid the recollection of the tertiary electrons emitted from the sample with few $\mathrm{eV}$ in energy and backscattered by the tank walls. The negative bias potential of -9 Volts was sufficiently low to neglect the deflection and deceleration of beam electrons with a few tens of $\mathrm{eV}$. The electron beam was pulsed to avoid surface charging of insulating material, whatever their thickness. The duration of each pulse was $10 \mu \mathrm{s}$. A contactless Kelvin probe was used to check that no surface charging built up during irradiation. Knowing $I_{f}$ and $I_{S}$, the EEY can be deduced thanks to the expression Eq.1 given below [16]:

$$
E E Y=\frac{I_{f}-I_{s}}{I_{f}}
$$

\section{Material Characterization}

A DAR400 X-Ray source from Omicron was used for the XPS analysis. It was equipped with $\mathrm{Mg} \mathrm{Ka}$ anode. The X-ray incidence angle was set to $45^{\circ}$ and the electron energy analyzer acceptance angle was normal to the surface. As the resolution depth of the XPS is close to that of the mean secondary electron escape depth (a few $\mathrm{nm}$ ), this analysis technique is suitable to investigate the effect of the chemical surface composition on the EEY.

\section{Experimental Conditions}

Two samples have been investigated in this work. The first one, referred as PNC, is a black conductive paint supplied by CNES. The second one was $100 \mathrm{~nm}$ thick silica $\left(\mathrm{SiO}_{2}\right)$ layer deposited on Si substrate [17].

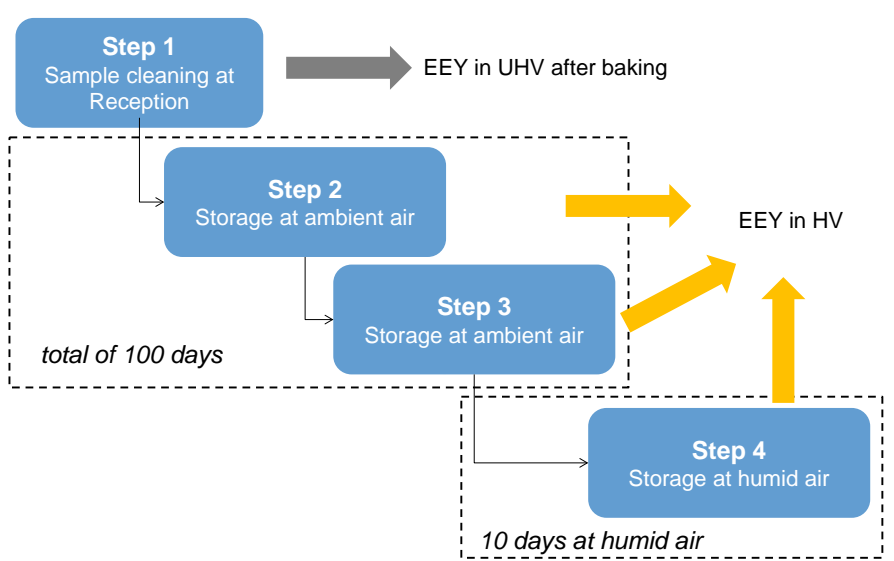

Fig. 2. Ground material ageing protocol

Several sample storage and operating conditions have been applied in order to represent ageing under atmospheric conditions and space conditions, see Fig. 2. The PNC and the $\mathrm{SiO}_{2}$ coating have been aged in four steps:

- $\quad$ step 1 : removal of contaminants from the surface with a sputtering flux of $500 \mathrm{eV}$ Argon ions perpendicular to the samples, aiming at restoring the original pristine sample.

- $\quad$ steps 2 : sample storage under atmospheric laboratory conditions for 40 and 65 days for $\mathrm{SiO}_{2}$ and PNC, respectively. Temperature was kept at $23 \pm 0.5{ }^{\circ} \mathrm{C}$ and moisture level at [45-65\%].

- $\quad$ steps 3 : sample storage under atmospheric laboratory conditions for 62 and 41 days for $\mathrm{SiO}_{2}$ and PNC, respectively (i.e. for a duration of around 100 days in total for both samples).

- step 4 : sample storage under high humidity level representative of conditions met before launch at Kourou, French Guyana (10 days). Humidity level of [93\%] was introduced at $40^{\circ} \mathrm{C}$.

The EEY yield have been measured after each step.

\section{EXPERIMENTAL RESULTS}

\section{A. Results for $\mathrm{SiO}_{2}$}

Results for $\mathrm{SiO}_{2}$ are first described here. Fig. 3 shows the XPS spectra measured on $\mathrm{SiO}_{2}$ surface after the initial argon sputtering (initial step). The surface is composed mainly by Oxygen and Silicon as expected and also some remained carbon contamination. The evolution of the surface composition during the storage conditions is shown in Fig. 4. 

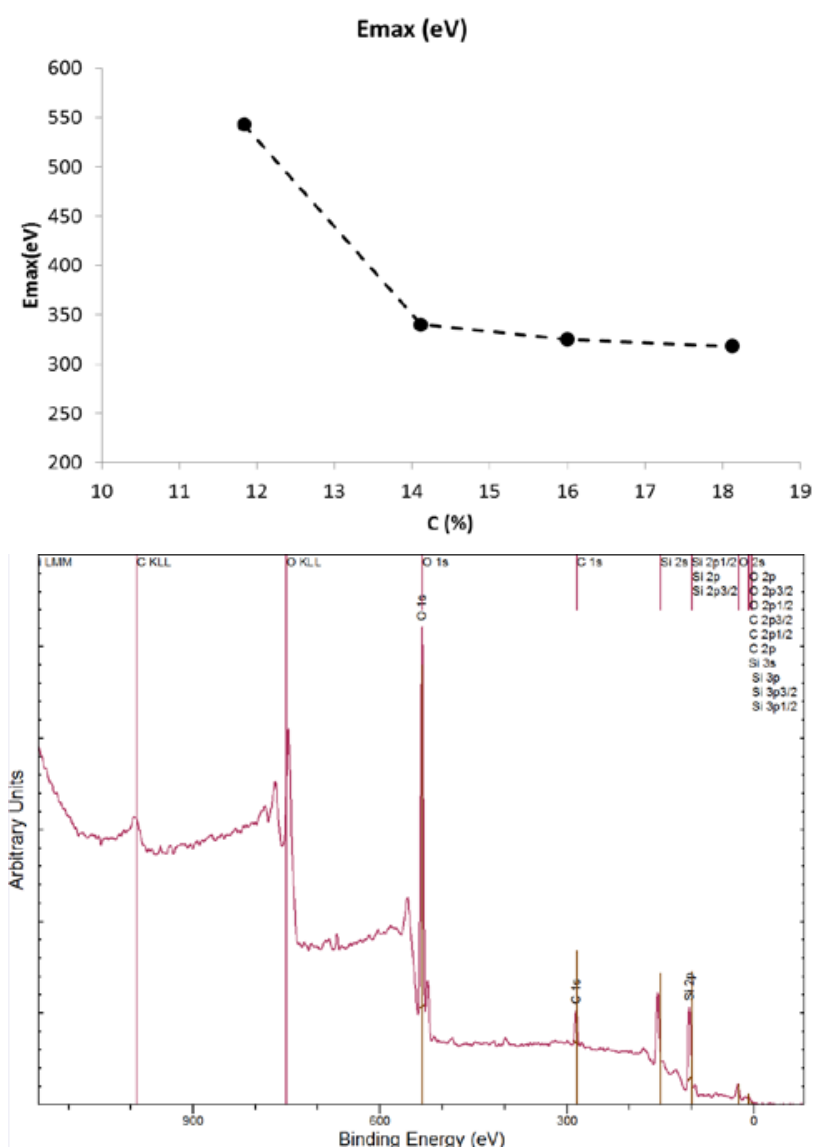

Fig. 3. XPS spectrum measured on the $\mathrm{SiO}_{2}$ after step 1

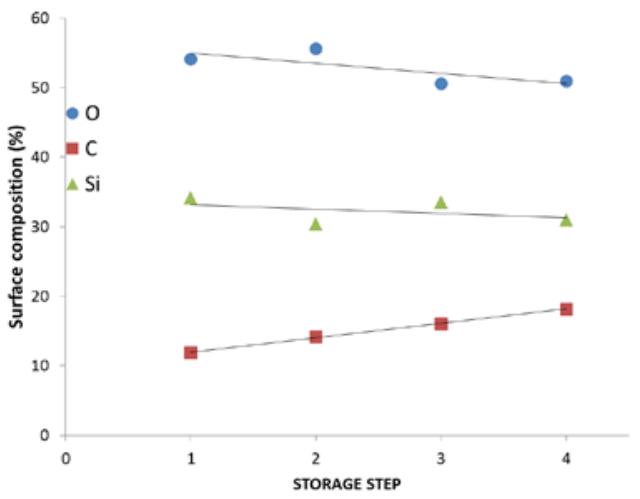

Fig. 4. Evolution of the elementary $\mathrm{SiO}_{2}$ surface composition (\% of silicon, carbon and oxygen) as function of the storage conditions, with straight line fits to guide the eyes.

The main noticeable result is the increase in the carbon content against silicon and oxygen $\left(\mathrm{SiO}_{2}\right)$. That illustrates how the exposition of the cleaned sample surface to the ambient atmosphere during steps 2 and 3 and thereafter to a wet atmosphere during step 4 leads to the deposition of hydrocarbon contamination layer [18].

Fig. 5 shows the evolution of the normalized EEY after each storage step as a function of primary electron energy. Each measurement was performed ten times. The dispersion of the results was lower than $5 \%$ at all energy. One significant effect of sample contamination during storage is the shift of the incident electron energy $E_{\max }$ that corresponds to the maximum of EEY. This shift is more pronounced after the first exposure to the ambient atmosphere during step 2. The following exposure to ambient atmosphere during step 3 and to the wet atmosphere during step 4 has only a moderate effect on $E_{\max }$. The thickness of the built-up hydrocarbon layer after step 2 was probably comparable to the mean secondary electron escape depth. This may explain the quasi-saturation tendency of $E_{\max }$ observed in Fig. 6. The second cross-over is shifted from around $20 \mathrm{keV}$ at step 1 down to around $10 \mathrm{keV}$ after step 4, which may affect spacecraft charging estimates.

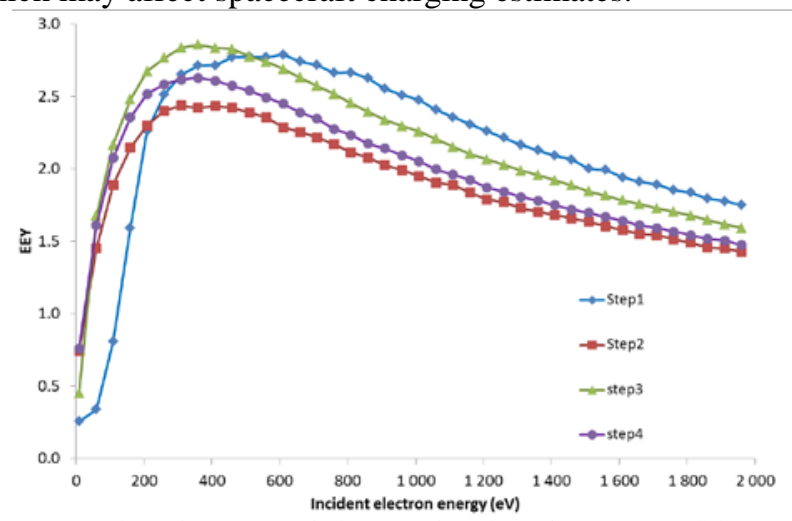

Fig. 5. Evolution of the EEY of $\mathrm{SiO}_{2}$ as a function of storage conditions.

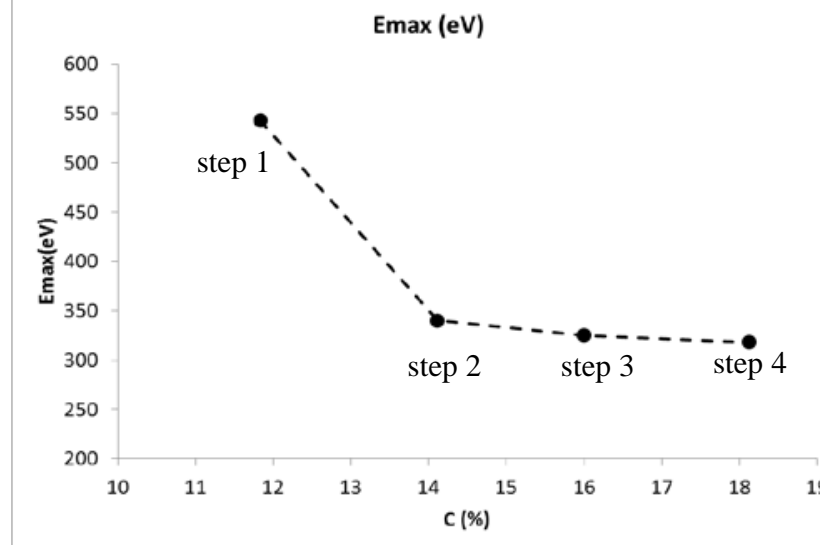

Fig 6. Evolution of $E_{\max }$ on $\mathrm{SiO}_{2}$ as a function of carbon concentration (contamination).

\section{B. Results for PNC}

The evolution of the PNC surface composition during the storage conditions is shown in Fig. 7.

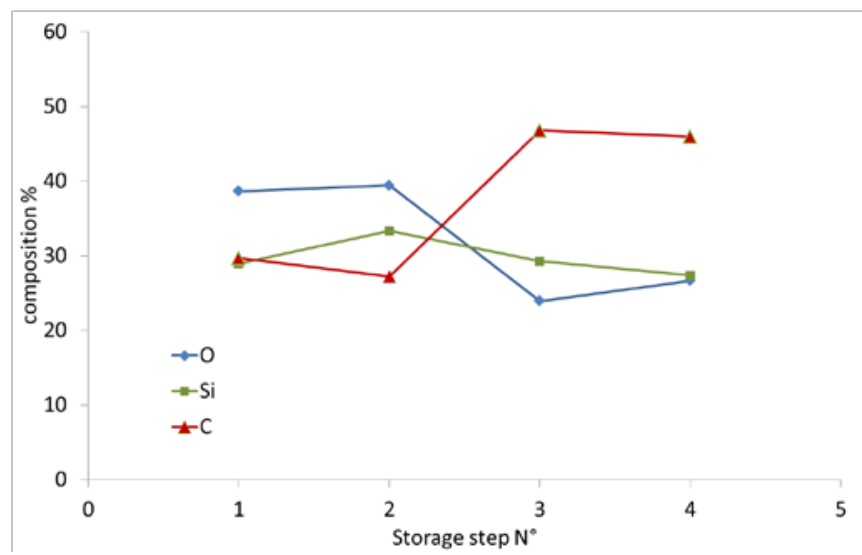

Fig. 7. Evolution of the elementary PNC surface composition (\% of silicon, carbon and oxygen) as function of the storage conditions 
The carbon content increased by $65 \%$ from step 1 to step 4 . Fig. 8 shows the evolution of EEY after each storage step as a function of primary electron energy. Only little change is observed between measurements performed at step 1 and step 4 , which should not impact spacecraft charging estimates.

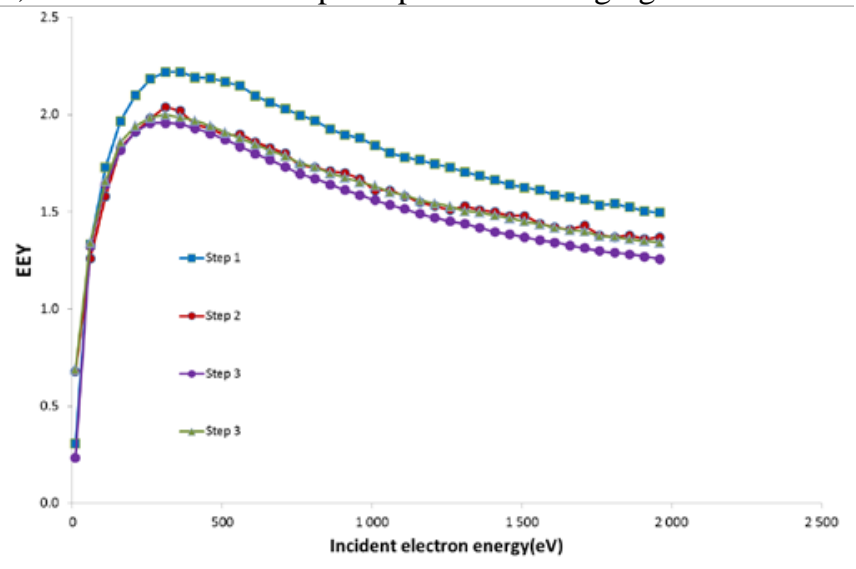

Fig. 8. Evolution of the EEY of PNC as a function of storage conditions.

\section{EEY Fits}

Analytical formulas are more suitable for numerical simulations than raw data. Fig. 9 presents two fits of the $\mathrm{SiO}_{2}$ EEY at step 4 using the Vaughan [18] and Dekker [19] models. Dekker's model better fits the experimental results than Vaughan's.

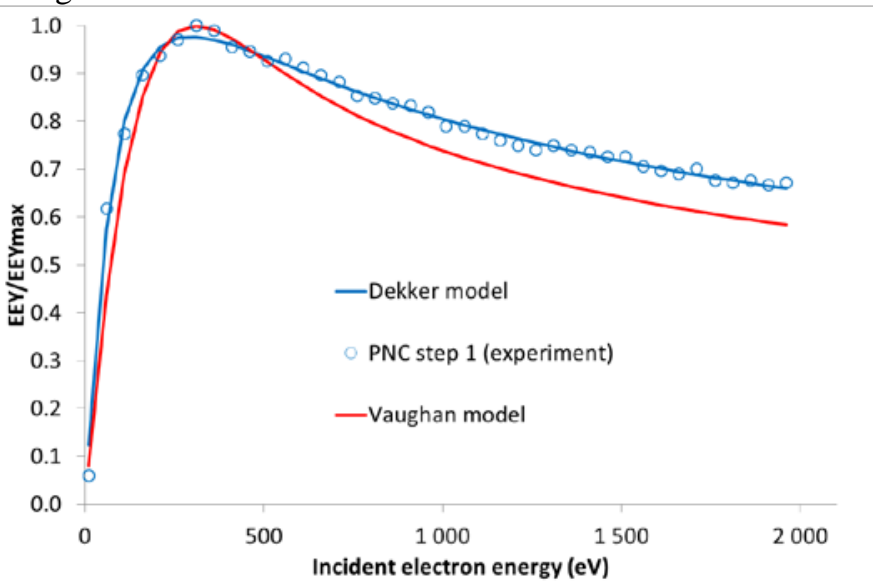

Fig. 9. Vaughan's and Dekker's models fits of the $\mathrm{SiO}_{2}$ normalized EEY at step 4.

\section{Numerical Simulation ANALYSIS}

In this section, we describe the inputs and results of simulations made to estimate worst-case surface charging of a GEO spacecraft. The version 5.2.4 of the SPIS software, freely available from the Spacecraft Plasma Interaction Network in Europe website (www.spis.org), has been used.

\section{A. Environments}

Two environments have been modelled. The first environment is the European Cooperation for Space Standardization (ECSS) worst-case for surface charging at GEO [9], which is a double Maxwellian fit of the event measured on SCATHA on April 24th, 1979 [20]. This environment is referred as ECSS WC. The second environment, referred as 3M SCATHA in this paper, is the triple Maxwellian fit of the same event [3]. There are important differences between these two Maxwellian fits. The latter is higher than the former at electron energies between 1-10 keV and inversely above $20 \mathrm{keV}$.

\section{B. Spacecraft Design}

Fig. 10 presents the geometry used to model a geosynchronous telecom spacecraft. It is composed of a central hub of dimensions $4.5 \mathrm{~m} \times 2.5 \mathrm{~m} \times 2.5 \mathrm{~m}$ covered with the conductive black paint (PNC) mentioned above, except the North and South faces covered partly with indium tin oxide (ITO) and partly with optical solar reflectors (OSR). Four antenna reflectors made of conducting material (mimicked by graphite material) are located around the hub. The larger antenna is circular with a diameter of $3.6 \mathrm{~m}$. Six solar panels are deployed. The size of each panel is $5 \mathrm{~m} \times 3.6 \mathrm{~m}$. The front side is made of coverglass and modelled with $\mathrm{SiO}_{2}$ material used in the experimental campaign described above. The rear side of the solar panels is made of PNC. The total size of the spacecraft is $39 \mathrm{~m}$.

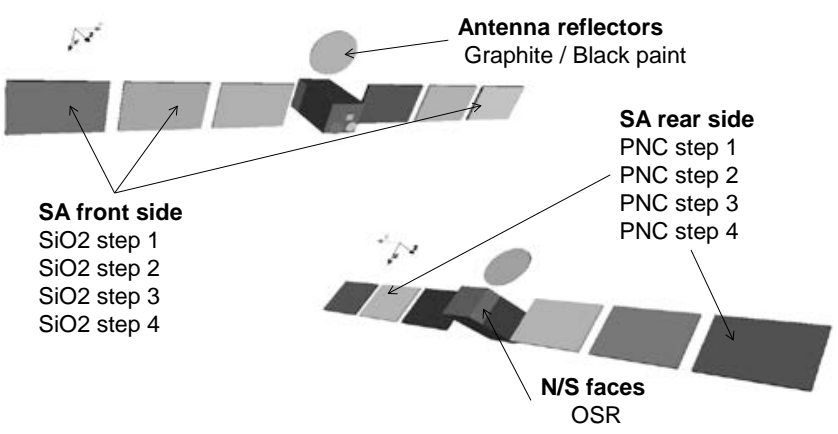

Fig. 10. Telecom spacecraft geometry

In this paper, the EEY of PNC and silica are used as inputs of the EEY model currently included in SPIS, i.e. the Vaughan model also used in NASCAP [7].

\section{ESD risk criteria}

The simulations are compared using two indicators of electrostatics discharge risks (ESD). The first indicator is the time necessary to get an inverted potential gradient (IPG) of $+300 \mathrm{~V}$ between solar cell cover glasses and their underlying ground structure. The second indicator is the time to get the same +300 V IPG level on OSR.

\section{Worst-CAse Charging Prediction}

\section{A. WC absolute charging in eclipse 'at equilibrium'}

The configuration leading to the worst absolute spacecraft charging is defined as the configuration leading to the most negative frame potential at equilibrium. It is not necessarily the worst conditions in terms of ESD risks. The worst frame potential of $-12.3 \mathrm{kV}$ is obtained with the ECSS WC environment for GEO and with the EEY properties of materials measured after step 4 (after contamination by ambient atmosphere and humidity). The time to reach an IPG of $+300 \mathrm{~V}$ 
on a solar cell cover glass and an OSR surface are 280 seconds and 210 seconds, respectively.

The second worst situation for absolute charging has been obtained with the ECSS WC environment for GEO and with the EEY material properties measured after step 1 . The frame potential is reduced to $-11.3 \mathrm{kV}$ due to a slight increase in the secondary electron current, consistent with the highest $E_{\max }$ obtained at step 1 . The time to reach an IPG of $+300 \mathrm{~V}$ on a solar cell cover glass and an OSR surface is 120 seconds and 320 seconds, respectively. The risk to trigger ESDs on solar cells is twice that of the previous configuration.

\section{B. WC SA charging in eclipse}

The configuration leading to the highest risk to trigger ESDs on the solar arrays (SA) in eclipse condition is with $3 \mathrm{M}$ SCATHA environment and with EEY properties measured after step 1, i.e. after cleaning. The equilibrium frame potential is about $-5.6 \mathrm{kV}$, which is half the frame potential, obtained in the configuration reported in Section V.A. The time to reach an IPG of $+300 \mathrm{~V}$ on a solar cell cover glass and an OSR surface is 45 seconds and 150 seconds, respectively. This is a direct effect of the enhanced flux of ambient electrons of energy between 1 and $10 \mathrm{keV}$; inducing larger secondary electron emission from surfaces with respect to electrons above $20 \mathrm{keV}$, see figure 13 of [3]. It results in increasing the difference of potentials due to high EEY of silica in this energy domain. Material properties obtained after step 1 exhibits a larger EEY than other steps. They results in larger ESD risks.

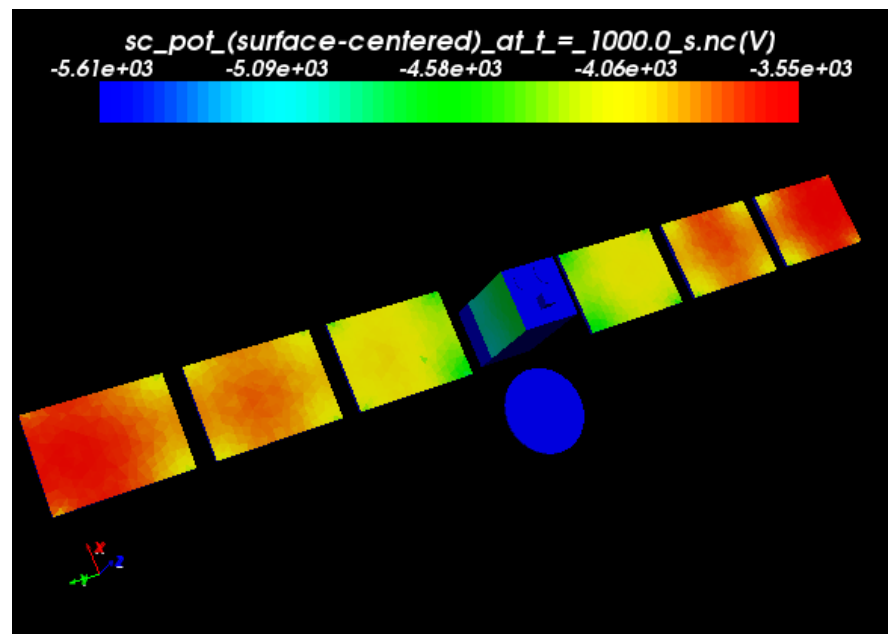

Fig. 11. Surface potential obtained with SCATHA 3M and with material properties measured after step 1.

Fig. 11 presents the spacecraft surface potential at equilibrium. External solar panels face the worst conditions with higher IPG levels than closer to the hub. The effect of the barrier of potential, which is imposed by the most negative surfaces on the SA surface, is less pronounced on the outer solar panels.

\section{WC OSR charging in eclipse}

The configuration leading to the highest risk to trigger ESDs on OSR in eclipse conditions is obtained with 3M SCATHA environment and with EEY properties measured after step 4. The equilibrium frame potential is about $-6.8 \mathrm{kV}$. The time to reach an IPG of $+300 \mathrm{~V}$ on a solar cell cover glass and an OSR surface is 110 seconds and 120 seconds, respectively.

\section{WC SA charging in sunlight}

The simulation results are very close to each other when the spacecraft is in sunlight, whatever the EEY properties. This is explained by the dominance of photoemission over EEY at 1 AU. The equilibrium frame potential is about $-4 \mathrm{kV}$ under $3 \mathrm{M}$ SCATHA environment. The time to reach an IPG of $+300 \mathrm{~V}$ on a solar cell cover glass and an OSR surface is 40 seconds and 200 seconds, respectively.

\section{DISCUSSION}

For the spacecraft geometry and materials used in this paper, the inverted gradient potentials reach $+300 \mathrm{~V}$ faster in sunlight in the 3M SCATHA environment definition. In these calculations, the +300 inverted gradient level is reached faster with the 3M SCATHA environment specification than with the ECSS WC environment. This environment results in both high level of absolute charging combined with increased EEY on solar cell cover glasses. It is worth reminding that this result is applicable to the present spacecraft configuration only. A different spacecraft design or choice of material properties could develop higher inverted gradient potentials in calculations with the ECSS WC environment than with the SCATHA 3M. Simulating an envelope of severe environments is thus recommended to predict the ESD risk with more confidence.

Exiting the Earth shadow needs also a special care because it allies two worst-case situations in series: equilibrium frame potential WC during eclipse followed by WC for solar arrays.

Another highlight of this paper is the importance to use material properties measured in appropriate conditions to get a proper estimation of the ESD risk in flight conditions. This remains challenging since the surface state of materials after a while in orbit is not yet fully known nor understood. Ultra-violet radiation from the sun, redeposited outgassed materials along with temperature variations, damage from energetic and not so energetic charged particles, exposure to electrical propulsion products if any, all modify the surface material. To be applicable to recently launched spacecraft, further tests could be performed to correlate these low coverage electron emission studies with a careful study of the outgassing rate of these materials, with careful attention paid to stimulated desorption processes due such mechanisms.

Depending on the outgassing levels expected during flight, one would use one EEY curve instead of one another. It shows the necessity to define an envelope of EEY curves to be used as parametric inputs to global scale numerical simulations, especially for materials that cover large areas. Therefore, EEY must be measured $1 /$ after representative sample storage conditions (including air hygrometry); 2/ under UHV; and 3/ after baking to the expected maximal flight temperature. Depending on the mission, however, actions should be taken during EEY measurements to remove contaminants according to expected flight conditions and possibly to account for ageing effects under radiative environment. Experimentally, this can be achieved using ion sputtering. In any case, it is highly recommended to keep track of sample surface state during tests. 
Finally, the numerical models of SPIS should include the Dekker model in the future to better account for the actual shape of EEY.

\section{ACKNOWLEDGMENTS}

This work was funded by CNES R\&D program 2017. The authors thank M. Villemant from ONERA for designing figure 1.

\section{REFERENCES}

[1] Choi, H.-S., J. Lee, K.-S. Cho, Y.-S. Kwak, I.-H. Cho, Y.-D. Park, Y.-H. Kim, D. N. Baker, G. D. Reeves, and D.-K. Lee, (2011), Analysis of GEO spacecraft anomalies: Space weather relationships, Space Weather, 9, S06001, doi:10.1029/2010SW000597

[2] Thomsen, M. F., M. G. Henderson, and V. K. Jordanova (2013), Statistical properties of the surface-charging environment at geosynchronous orbit, Space Weather, 11, 237-244, doi:10.1002/swe.20049.

[3] Matéo-Vélez, J.-C., Sicard, A., Payan, D., Ganushkina, N., Meredith, N. P., \& Sillanpäa, I. (2017). Spacecraft surface charging induced by severe environments at geosynchronous orbit. Space Weather, 15. https://doi.org/10.1002/2017SW001689

[4] Mizera, P.P. (1981), Charging Results from the Satellite Surface Potential Monitor, Journal of Spacecraft and Rockets, Vol. 18, No. 6, pp. 506-509. https://doi.org/10.2514/3.57848

[5] Roussel, J.-F. , G. Dufour, J.-C. Mateo-Velez, B. Thiébault, B. Andersson, D. Rodgers, A. Hilgers and D. Payan (2012), SPIS multi time scale and multi physics capabilities: development and application to GEO charging and flashover modelling, IEEE Trans. Plasma Sci., Vol 40, $\mathrm{N}^{\circ} 2$

[6] Thiebault, B., B. Jeanty-Ruard, P. Souquet, J. Forest, J.-C. Mateo Velez, P. Sarrailh, D. Rodgers, A. Hilgers, F. Cipriani, D. Payan and N. Balcon (2016), SPIS 5.1, an innovative approach for spacecraft plasma modelling, IEEE Transactions on Plasma Science, Vol 43, pp 2782-2788. doi: 10.1109.TPS.2015.2425300

[7] Mandell, M. J., V. A. Davis, D. L. Cooke, A. Wheelock, C. J Roth (2006), Nascap-2k Spacecraft Charging Code Overview, IEEE Trans. Plasma Sci., Vol. 34, No. 5.

[8] Muranaka, T. , S. Hosoda, J. Kim, S. Hatta, K. Ikeda, T. Hamanaga, M. Cho, H. Usui, H. O. Ueda, K. Koga and T. Goka (2008), Development of multi-utility spacecraft charging tool (MUSCAT), IEEE Trans. Plasma Sci., Vol 36, N5.

[9] ECSS (2008), ECSS-E-ST-10-04C, Space environment (http://ecss.nl/standard/ecss-e-st-10-04c-space-environment/)

[10] NASA (2011), NASA-HDBK-4002A, Mitigating In-Space Charging Effects-A Guideline.

[11] Hong SY, Yeh PC, Lee I, Yu J, Dadap JI, Nuckolls C, et al. Coverage-Dependent Modification of the Surface Electronic Structure of an Organic-Semiconductor-Adsorbate Layer. Journal of Physical Chemistry C 2014;118:6214-25.

[12] Engelhart DP, Wagner RJV, Johnsen PC, Wodtke AM, Schaefer T. Adsorbate enhancement of electron emission during the quenching of metastable $\mathrm{CO}$ at metal surfaces. Physical Chemistry Chemical Physics 2015;17:11540-5.

[13]Chang WY, Dennison JR, Kite J, Davies RE, "Effects of Evolving Surface Caontamination on Spacecraft Charging," Paper AIAA-2000-0868, Proceedings of the 38th American Institute of Aeronautics and Astronomics Meeting on Aerospace Sciences, (Reno, NV, 2000).
[14] T. Gineste, M. Belhaj, G. Teyssedre, and J. Puech, Investigation of the electron emission properties of silver: From exposed to ambient atmosphere Ag surface to ion-cleaned Ag surface (2015), Appl. Surf. Sci, 359, p 398

[15] N. Hilleret, C. Scheuerlein and M. Taborelli, The secondary-electron yield of air-exposed metal surfaces, Applied Physics A 76, N², pp 1085-1091

[16] M Belhaj, T. Tondu, V. Inguimbert J. Phys. D: Appl. Phys. 43 (2010) 135303

[17] M. Belhaj, K. Makesheva, S. Dadouch, ONERA report 2016-035-25730 (2016)

[18] J. R. M. Vaughan, A new formula for secondary emission yield, IEEE Trans. Electron Devices (1989), Vol. 36, N99, pp. 1963-1967

[19] Dekker, A.J., Secondary Electron Emission (1958) Solid State Physics, Vol 6, pp 251-311

[20] Gussenhoven, M.S. and E. G. Mullen (1983), Geosynchronous environment for severe spacecraft charging, J. Spacecraft and Rockets 20, Nº 1 , p. 26 